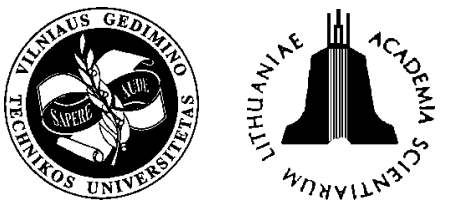

\title{
THE ANALYSIS OF WEAR INTENSITY OF LUBRICATED AND UNLUBRICATED LOCOMOTIVE WHEEL SETS FLANGES
}

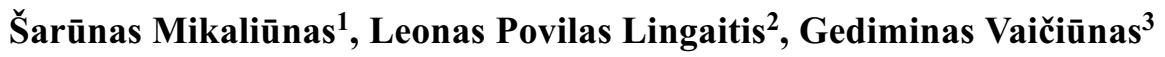 \\ Dept of Railway Transport, Vilnius Gediminas Technical University, \\ J. Basanavičiaus g. 28, LT-03224 Vilnius-09, Lithuania
}

Received 2003-11-14; accepted 2004-01-15

\begin{abstract}
The wear dynamics of wheel - set tyres of diesel locomotives was investigated. Basing on research results it is possible to predict wheel-tyre safety margin, to improve maintenance and to state the periodicity of repair, as well as most efficiently to use traction rolling-stock repair funds
\end{abstract}

Keywords: railway, locomotive, wheel set flange, intensity of wear, lubrication.

\section{Introduction}

Wheel-sets are the most heavily wearing locomotive units often requiring expensive repair.

Rolling stock safety and uniform motion largely depend on their performance. Therefore, it is extremely important to determine the intensity of the wheel-set wearing at various stages of their service life. The analysis of the above characteristics will enable us to determine more accurately the safety margin of the wheel tyres and the supply of spare wheel sets needed by a locomotive park, as well as to establish the optimal servicing and repair intervals, allowing more efficient allocation of expenses on rolling stock repair.

\section{Research object and aims}

The wearing of the wheel tyres is caused by two factors. The first is plastic deformation when the metal is forced out from the running surface towards the flange. The second is a thermal effect taking place in wheel spinning or stopping of the locomotive. This causes the formation of a hard martensite structure on the running surface.

Heavy deformations of the wheel tyres and railhead occur due to long - term wheel and rail interaction. In this case a cyclic effect of contact stresses can cause a residual deformation. Though it can not completely de-

\footnotetext{
${ }^{1}$ smikal@ti.vtu.lt,

2 leonasl@ti.vtu.lt

${ }^{3}$ vaic@ti.vtu.lt
}

stroy the wheel tyre, normal operation may be disturbed by vibration and dynamic loads.

The change of the wheel tyre dimensions depends on the wear of the running surface which is determined by a cut size (i) (Fig 1) as well as by the reduction of the flange thickness (a) (known as natural wearing). These transformations also depend on the removal of a metal layer while recovering the thickness and height of the flange by turning the wheel tyre and its running surface (known as technological wear), being, therefore, determined by the general wear intensity.

A major factor affecting the flange (a) wear is its sliding relative to the rail during the movement of the locomotive when it is either approaching the profile plane of the rail head or departing from it $[1,2]$. Due to the $(10$ $\mathrm{mm}$ ) gap between the flange and the rail head the wheelsets are swaying. Regular wheel tyre flange movement towards and away from the rail is a major cause of their intensive wear.

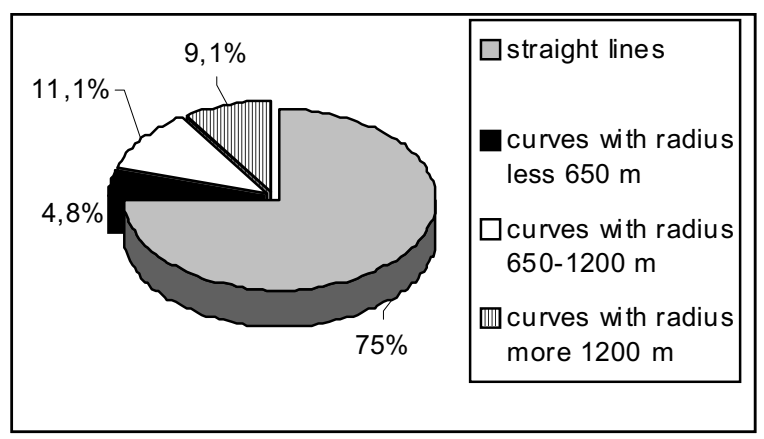

Fig 1. Lithuanian railway length distribution based on track curvature radius 
The wearing of the locomotive wheel-sets is also caused by a number of minor factors, i.e. chemical composition of the wheel tyres, physical properties and uniformity of the metal used, quality of manufacture, strength factors, climatic conditions, loading conditions, operation under maximum load, air temperature, humidity and dust content, the pollution of wheel-tyre surfaces with abrasive materials (e.g. putting sand between the wheels and rails), track condition determining the dynamic load intensity, speed of the locomotive, lubrication of the contact points of the wheel and the rail, etc.

The character of wheel tyre wear as a complex factor can be determined by site tests.

In order to reduce the wearing of the wheel tyre flanges lubrication system should be provided in a locomotive. One of such systems is FluiLub - wheel tyre lubrication system made by Baier + Köppel, a German firm. It supplies oil to the tyre flange when the locomotive is running along the curved track sections, with the most heavy friction between the flange and the rail. Depending on the direction of the locomotive movement the flanges of the front wheel-sets of every locomotive section are lubricated.

The tests [3-5] performed did not yield any relationships concerning the wearing intensity of the wheel tyre flanges and the running surfaces during their service life $[6,7]$. Therefore, currently accepted intervals between the repairs of the wheel-sets by turning them are not rational as well as being practically unpredictable. This is one of the reasons why the railroad companies experience additional losses from not timely turning the wheel-sets or due to the decrease of their durability caused by the removal of a layer of metal in this operation.

The main objective of the present research is to determine major trends of wheel-sets wearing in order to be able to predict repair intervals, as well as determining their distance run between overhauls allowing to plan the number of repairs and spare wheel-sets to be purchased.

\section{The experiment}

Two locomotives 2M62 (each of them having 12 wheel-sets in two sections), not provided with wheel tyre lubrication systems, and one locomotive 2M62 having a German Baier + Köppel FluiLub system to lubricate tyre flanges were chosen.

At the beginning of the experiment all the wheelsets were new, with their tyre dimensions conforming to the rated parameters given in Table 1.

The average distance run between the measurements of the locomotives not provided with a wheeel tyre lubrication system was 10,8 thous. $\mathrm{km}$, while for those having such systems it reached 10,5 thous $\mathrm{km}$. The locomotive wheel-sets were measured in the locomotive depot in Vilnius.
Table 1. Main control dimensions of wheel tyre profile

\begin{tabular}{|c|c|c|c|}
\hline $\begin{array}{c}\text { Dimensions } \\
\text { verified }\end{array}$ & $\begin{array}{c}\text { The largest } \\
\text { wheel tyre } \\
\text { cut } i, \mathrm{~mm}\end{array}$ & $\begin{array}{c}\text { Flange width } \\
a, \mathrm{~mm}\end{array}$ & $\begin{array}{c}\text { Wheel tyre } \\
\text { thickness } h, \\
\mathrm{~mm}\end{array}$ \\
\hline Initial (rated) & 0 & 33 & 77 \\
\hline Limiting & 7 & 25 & $36^{*}$ \\
\hline
\end{tabular}

* this thickness of the wheel tyre is reached when its running surface is turned to recover the required profile when the flange is heavily worn - out (with a $<25,0 \mathrm{~mm}$ ).

The intensity of wearing of the locomotive wheel tyres and their flanges in particular largely depend on the extent of track curvature. Therefore, the locomotives being investigated ran along the tracks with the curvature radius common to Lithuanian railroads. The radii of the curved tracks of Lithuania are given in Fig 1.

From Fig 1 we can see that the relationship between straight and curved railroad sections in Lithuania is 1:3.

It was assigned that oiled and not oiled wheel tyres would operate under the same conditions, i.e. running along the same track sections. The work performed by them (tkm brutto) should also be the same, while both sections of each locomotive would always operate simultaneously.

The data on the lubricant used for oiling the wheel -sets are given in Table 2.

Measurements of the cut in the wheel tyre and the thickness of its flange were made by a specially programmed gauge (Fig 2). A wheel - set tyre is located so that it could rotate. A measuring device can move along the axles of the wheel, therefore, putting it in the required position allows us to measure both the tyre cut and the flange wear.

The scheme of measuring the wheel tyre cut and flange width is given in Fig 2.

All measurements are made according to special programs available in the device. First, the thickness

Table 2. Characteristics of the lubricant for wheel set oiling

\begin{tabular}{|l|c|}
\hline Characteristic & Value \\
\hline Dynamic viscosity & $900-1000 \mathrm{mPa}$ \\
\hline Density at $20{ }^{\circ} \mathrm{C}$ & $1050 \mathrm{~kg} / \mathrm{m}^{3}$ \\
\hline Operating temperature & From -40 to $+90{ }^{\circ} \mathrm{C}$ \\
\hline Allowable $t^{\circ}$ of area surface & From -100 to $+500{ }^{\circ} \mathrm{C}$ \\
\hline Solvability in water at $25^{\circ} \mathrm{C}$ & $0,2 \mathrm{~kg} / \mathrm{m}^{3}$ \\
\hline Friction coefficient & 0,1 \\
\hline Boiling $\mathrm{t}^{\circ}$ & $250{ }^{\circ} \mathrm{C}$ \\
\hline Flashpoint $\mathrm{t}^{\circ}$ & $300{ }^{\circ} \mathrm{C}$ \\
\hline Decomposition $\mathrm{t}^{\circ}$ & $350{ }^{\circ} \mathrm{C}$ \\
\hline Biological disintegration & $90 \%$ \\
\hline Period of keeping quality & two years \\
\hline
\end{tabular}




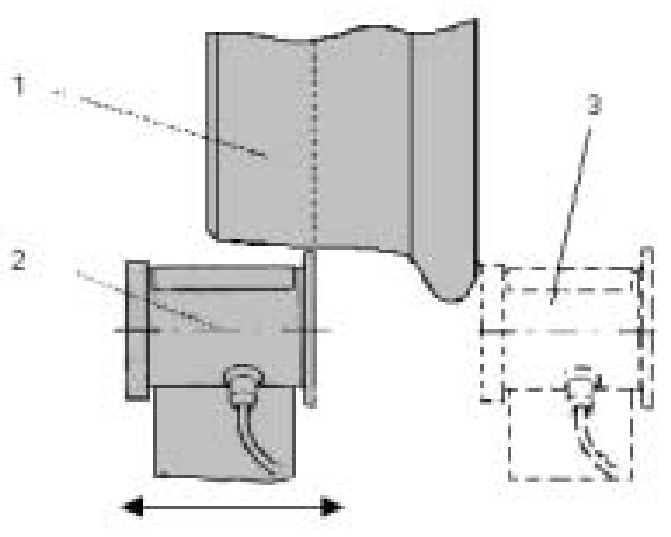

Fig 2. Scheme of flange width measurement

gauge is supported against the internal surface of the wheel (the initial gauge position, see Fig 2). In this way the gauge length for measurements in the horizontal plane is obtained. When the gauge moves to the outside surface of the wheel, its coordinate on the top of the flange is fixed.

This is the gauge length in the vertical plane. When the wheel is revolving, the gauge is supported against it at the point where measurements should be made. The program compares the current coordinates of the gauge with the basic coordinates. Basing on this, the values of the parameter to be obtained are calculated.

The values of the largest tyre cuts of every wheel (along its perimeter) and the flange wear are registered in the database.

During the experiment the mileage of a locomotive between the beginning of the experiment and each measurement was also logged.

The measurement error of the cut and flange thickness was $\pm 0,05 \mathrm{~mm}$.

The following wheel tyre parameters were verified: wheel tyre cut (i) and flange width (a).

\section{The obtained results}

In the experimental period the highest mileage for the wheel-sets not provided with a lubrication system was 135,5 thous. $\mathrm{km}$, while for those having a lubrication system it reached 141,6 thous. $\mathrm{km}$.

The values obtained for the parameters verified, with the fixed mileage values, are random variables. Therefore, the dependence of these parameters on mileage is determined by means of a regressive analysis. The direction line reveals the trend and the character of the change of this sequence of data. With the help of Excel 2000 software package the polynomials - mathematical expression of curves - were calculated. In this way the data were processed and the following regression equations obtained:

- for the cut (without lubrication and with lubrication):

$$
i=2 \cdot 10^{-5} \cdot L-3 \cdot 10^{-11} \cdot L^{2},
$$

graphical representation of these data is shown in Fig 3;

- for flange wearing intensity:

without lubrication:

$$
A=0,123 \cdot 10^{-3} \cdot L-0,122 \cdot 10^{-8} \cdot L^{2}+0,475 \cdot 10^{-14} \cdot L^{3},
$$

with lubrication:

$A=0,744 \cdot 10^{-4} \cdot L-0,674 \cdot 10^{-9} \cdot L^{2}+0,246 \cdot 10^{-14} \cdot L^{3}$,

here $i$-is the cut, $\mathrm{mm} ; L$ - mileage, $\mathrm{km} ; A$-intensity of flange wear, $\mathrm{mm}$.

The curves representing flange wearing are given in Fig 4.

The comparison of the data obtained shows that the intensity of wear of the locomotive wheel tyre flanges is twice as high as that of the cut formation. Thus, the wearing of wheel tyre flanges is the main factor determining

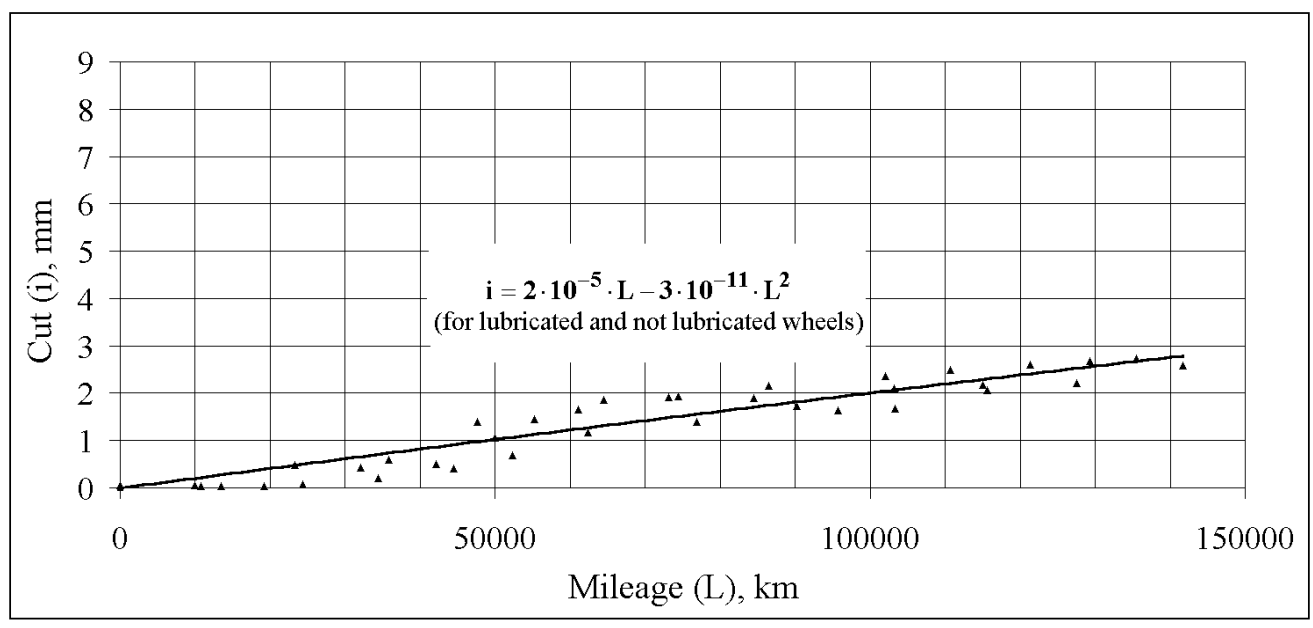

Fig 3. Dependence of wheel cut value on mileage 


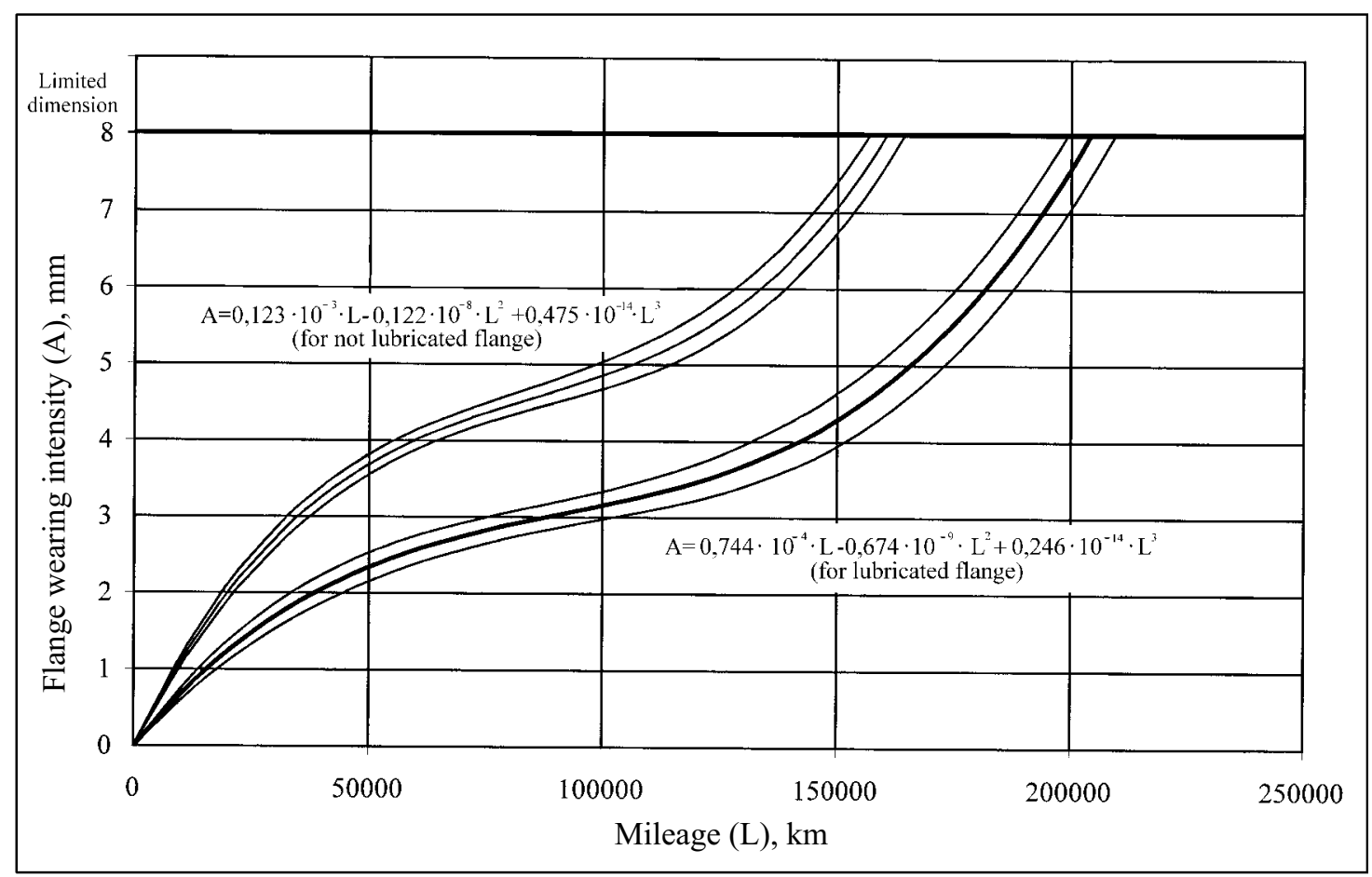

Fig 4. Intensity of wheel flange wearing

the time between wheel tyre overhauls.

It is possible to state that lubrication has no significant effect on the rate of cut formation (Fig 3).

The regression equations obtained also show that the cut is increasing uniformly throughout the total service period, while the flange wearing (Fig 4) is most intensive at the beginning of service until the mileage reaches $30-40$ thous. $\mathrm{km}$, with the worn-out layer being $1,5-2,5 \mathrm{~mm}$. This proves a well-known fact that more intensive flange wearing takes place until the wheel tyre profile acquires the shape of the rail head [7-10]. Then the intensity of wear decreases, increasing only when the mileage comes up to 150 thous. $\mathrm{km}$.

The relationship obtained allow us to predict that turning of the wheel-sets because of worn-out flanges should be performed when the mileage of 160 thous. $\mathrm{km}$ is reached since the beginning of service of the wheel tyres, not provided with a lubrication system. When wheel tyre flanges are lubricated the limit is 210 thous. $\mathrm{km}$. The accuracy of the calculated data is $\pm 2 \%$ (with $95 \%$ probability). Thus, it may be stated that the use of a lubrication system can increase wheel tyre service life by at least 1,3 times.

\section{Conclusions}

1. The study into wheel rim wheel flange abrasion showed that the wheel flange is abraded more intensively at the beginning of the exploitation up to the locomotive run (30-40) thous. km until the first (1,5-2,5) mm abrade. Then the intensity of abrasion reduces. It continues increasing from 150 thous. $\mathrm{km}$.

2. The wearing intensity of the flange of the locomotive wheel tyres is about two times heavier than the increase of the cut, therefore the time between wheelsets overhauls is determined by the extent of flange wear.

3. It is possible to predict that the flange will be worn out to the limiting width after running $160 \pm 3$ thous. $\mathrm{km}$ without lubrication and after $210 \pm 4$ thous. $\mathrm{km}$ of mileage if it is lubricated.

4. The provision of a lubrication system for the wheel set flanges increases the mileage of the wheel-sets until turning is needed up to $31 \%$.

5. Prediction mathematical models (1)-(3) of wheelset wear simulated by the authors enable to predict the intensity of wheelsets wheel rim wear at the reliability of $95 \%$ during separate stages of exploitation as well as the rest exploitation resources until repair when the lubrication system of locomotive wheelsets wheel flange abrasion is used or not used.

\section{References}

1. Kurasov, D. A. Increasing durability of wheel-sets of rolling stocks (Повышение долговечности бандажей колесных пар подвижного состава). Moscow: Transport, 1981. 160 p. (in Russian). 
2. Wrang, M. Single-axle running-gear. Stockholm: Royal institute of technology, 1995. $136 \mathrm{p}$.

3. Grieve, D. G.; Dwyer-Joyce, R. S.; Beynon, J. H. Abrasive wear of railway track by solid contaminants. Journal of Rail and Rapid Transit, 2001, Vol 215, p. 193-205.

4. Gnedenko, B. V.; Beliajev, J. K.; Solovjov, A. D. The use of mathematical methods in the theory of reliability (Математические методы в теории надежности). Moscow: Nauka, 1965. 367 p. (in Russian).

5. Zhai, W. M.; Sun, X. A detailed model for investigating vertical interactions between railway vehicle and track. Vehicle System Dynamics, 1994, Vol 23 (Suppl.), p. 603615.

6. Moreau, A. Characteristics of wheel/rail contact. Rail Engineering. International Edition, 1992, No 3, p. 15-22.
7. Manual of the formation, maintenance and repair of the wheel-sets for $1520 \mathrm{~mm}$ - gauge traction rolling stocks (1520 mm pločio vèžès traukos riedmenu aširačiu formavimo, remonto ir priežiūros instrukcija). Vilnius: L G informacijos ir leidybos centras, 1999. 128 p. (in Lithuanian).

8. Wu, T. X.; Thompson, D. J. Theoretical investigation of wheel/rail non-linear interaction due to roughness excitation. Vehicle System Dynamics, 2000, Vol 34 (4), p. 261-282.

9. Gurule, S.; Wilson, N. Simulation of wheel/rail interaction in turnouts and special track work. Vehicle System Dynamics, 1999, Vol 33, p. 143-154.

10. Mikaliūnas, Š.; Lingaitis, L. P.; Subačius, R. Analysis of locomotive wheel sets wearing. Transport, Vol XVII, No 1, Vilnius: Technika, 2002, p. 3-7. 